\title{
Turismo Internacional no Rio de Janeiro - Mecanismos de Acumulação Externa ao Lugar ${ }^{1}$
}

\author{
José Augusto Guedes Falcão ${ }^{2}$
}

RESUMO: Análise da expansão da economia do turismo no setor do receptivo internacional no Rio de Janeiro, embasada em processos relacionados a formas de integração econômica de lugares e regiões desigualmente desenvolvidos.

PALAVRAS-CHAVES: Turismo internacional; circulação e transferência de renda; Rio de Janeiro; Brasil.

ABSTRACT: The objective of this paper is to analyse the expansion of tourism economy in the international tourist attendance in Rio de Janeiro City. It is based on processes related to economic integration of unequaly developed places and regions.

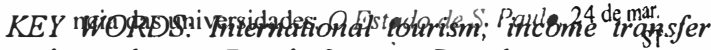
and circulation; Rio de Janeiro; Brasil.

\section{Infrodução}

Produto das formações sociais desenvolvidas, onde a informação e as inovacões tecnológicas assumem um papel preponderantes, a economia do turismo re expande pelo mundo, alargando as fronteiras do processo de acumulação e reprodução do capital através do consumo do espaço.

\footnotetext{
1. Opresente trabalho foi extraido da Dissertação de Mestrado "Turismo Internacional no Rio de Janeiro - Mecanismos de uma reflexảo Transferência de Renda “, apresentada no Instituto de Geociências da UFRJ em maio de 1993, e não contém No obstante, conside nuadro monetário nacional, que se consubstancia com a introdução do Real em julho de 1994.

2 Arquiteto

PlanejamentoU SECPLAN (RJ) fonnado pela Faculdade de Arquitetura e Urbanismo da UFRJ. Pós-graduado em Geociências da Urano e Regional pela UERJ e pela Universidade de Roma/Itália. Mestre em Geografia pelo Instituto de End para corresp. R Ra Almirante Alexandrino, 3.780, Bloco F, apto.101 - 20.241-262, Rio de Janeiro, RJ, Brasil.
} 
O turismo constitui-se hoje em uma atividade econômica promissora nos países desenvolvidos e no mercado internacional extendendo-se, inclusive, para áreas e locais periféricos, a despeito das limitações dos seus mercados de consumo interno. O Brasil e o Rio de Janeiro enquadram-se nesta forma de expansão.

Como se realizam os fluxos de renda que são gerados pela atividade, estabelecer esta relação econômica entre regiões ricas e desenvolvidas e lugares periféricos ou semi-periféricos? No âmbito do mercado internacional, como realiza o processo de circulação dos valores produzidos pela atividade e mecanismos específicos ela propicia, no que diz respeito à transferência ou retenção de excedente nos pontos onde se concentram determinadas condições de controle da economia internacional?

Tanto mais complexa se torna esta questão, quanto mais se expande e se integra a economia mundial, não só na esfera do consumo, mas também na esfera da produção. O turismo internacional consolida-se por este duplo caminho.

Do ponto de vista metodológico, a adoção dos pressupostos teóricos do desenvolvimento geograficamente desigual, conforme Soja (1983), relativisa e objetiva o encaminhamento da questão a uma determinada forma crítica de ver e entender a realidade.

No contexto das novas formas de internacionalização das realçoes de produção e consumo e da divisão internacional do trabalho, as especificidades da economia do turismo e da comercialização de serviços locais diretamente no mercado externo possibilitam a concorrência de mecanismos de transferência - ou retenção - de renda no Exterior. Esses mecanismos consolidam e reforçam, na sua esfera de atuação, a espacialidade desigual do capitalismo contemporâneo.

\section{Espaço Desigual e Integração de Lugares Periféricos}

A economia contemporânea se articula à escala planetária, acima das distinções e peculiaridades territoriais sejam elas políticas, socioculturais ou da organização da produção. Este processo é motor e resultado do desenvolvimento científico e tecnológico e de uma evolução sem precedentes das inovações nos transportes e nas comunicações, que possibilitam uma conexão imediata e simultânea de áreas distantes e até então isoladas.

Tal conexão não se refere apenas às relações de troca interregionais e internacionais e aos tradicionais fluxos de bens característicos do período mercantil. Trata-se de uma nova organização, ao nível da produção, que define uma divisãa internacional do trabalho e que estabelece um conjunto novo de relações e de serviços, através de fluxos de pessoas, de tecnologias, de informações, de capitais etc. Estes fluxos realizam-se através de um conjunto de redes diversas que constituem a base das novas formas de organização do espaço.

No âmbito dessa nova ordem econômica mundial novos territórios são ercado producivo que se torma transna da dução ao consumo, induzem a uma especialização de regiões e países, consoli位ãa espacial do trabalho e reforçam processos de dominação da ecentrais.

conomia por par Alain Lipietz, a arborescência do terciário moderno é apenas uma Segundo Alain unilateral das leis permanentes de acumulação capitalista expressão para, centralização do capital, desapropriação do "savoir-faire" dos

(concentraçatuores diretos etc.).

Aterciarização da sociedade e a irmã gêmea da polarização internacional, e elas derivam A uma causa única: a forma da divisão do trabalho imposta pela acumulação capitalista. (Lipietz, 1988:207).

Assisti-se, assim, a produção de um espaço dialeticamente integrado e fragmentado, onde o desenvolvimento científico e tecnológico tem um papel importante como indutor/induzido deste processo e onde o conhecimento e o controle da informação se colocam como fundamentais no domínio sobre mercado. Equalização e diferenciação são geradoras de um desenvolvimento geograficamente desigual, que forma e é formado pelos processos de desenvolvimento e reprodução capitalista.

Por razôes inequivocas, o desenvolvimento do capitalismo concreto tende a estruturar o espaço em áreas de dominância e subordinação, autoridade e dependências relativas, acumulação ampliada através de apropriação externa do valor e acumulação simples através de transferência externa de valor (1). As estruturas de desenvolvimento geogradistintas. Dentro do sistema capitalista mundial, o desenvolvimente geograficamente desigual é a expressāo de uma divisão internacional do trabalho, descrito mais amplamente em termos de centro/periferia, mas restritamente padronizado numa ordem de Estados Nação "desenvolvidos" diferencialmente e de territórios dependentes, formações sociais primárias, cada qual com sua mescla particular de atividades produtivas (Soja, 1983.59).

A produção diferenciada do espaço define uma articulação altamente heconômizada do mesmo e reproduz, em várias escalas, relações de dominação Nos centros sobre as periferias.

Nestes processos economicamente "integradores", assume uma importância cada vez maior a circulação de bens imateriais. Eles disseminam sobre "território" formas novas de consumo não material. O comércio internacional não manufaturador pensado somente em termos de produtos primários e de bens Noans.

No âmbito deste comércio internacional de serviços, da sua expansão e da conseqüente divisão internacional do trabalho e especializações regionais 
decorrentes, o turismo e o lazer surgem como uma via potencial de integração de alguns países ou regiões periféricas, constituindo-se assim numa novà fronteira modal ${ }^{3}$ e territorial do processo de acumulação.

\section{Turismo: uma Fronteira em Expansão}

O turismo, qualificado como uma nova modalidade de consumo de mass desenvolve-se no âmbito da emergente economia das trocas invisíveis em escal nacional e internacional. Esta modalidade se expande com a produção de ben (infra-estrutura, construções, alimentos e produtos diversos) c serviços (transpor. tes, hospedagem, alimentação etc.) que se integram para o consumo final Est conjunto de bens e serviços oferece ao mercado de cons!ımo as "condic̃ acessibilidade" a um determinado lugar. O espaço, na dimensão do lugar, assume o caráter de objeto de consumo e, como tal, é (re)produzido c comercializado.

Seja reforçando c induzindo a sua cstruturação e qualifícação, no caso de áreas novas que a atividade integra ao seu circuito de produção/consumo, seja na utilização dessa estruturação e qualificação em áreas já solidamente integradas a outros circuitos da produção/reprodução - centros urbanos já consolidados, 0 turismo é uma atividade econômica que tem nestas qualidades do espaço, que caracterizam e identificam o lugar onde ele se desenvolve, um pressuposto fundamental a sua realização.

A cstruturação e qualificação do lugar propiciam a sua acessibilidade aos mercados de consumo, sejam clas diretamente promovidas pelos agentes ligados ao sctor através de equipamentos receptivos e mcios de transportes ou, indiretamente pela infra-cstrutura c equipamentos urbanos colctivamente realizados tais como cstradas, portos, aeroportos etc

O "consumo do espaço "se coloca assim como uma forma de acumulação própria, integrando territórios aos "cspaços de consumo" tradicionais que coincidem com os locais históricos de acumulação do capital, scja pela descoberta de novos lugares, seja pela revalorização e reciclagem destes tradicionais "espaços de consumo" em "espaços para o consumo". A superposição destas funções reforça duplo caráter da centralidade capitalista: lugar de consumo c consumo de lugar

Desta forma, estrutura-se o que se convencionou chamar de "indústria do turismo", em alguns casos responsável direta pela integração de determinadas periferias aos circuitos modernos da produção.

Trata-se de um mercado oportuno aos parâmetros da economia mundial contemporânca c seuscircuitos "intura âs parametros da economia me cada vez maior importância e a produtividade industrial, decorrente dos avanços cientificos maior importancia e a produtividade industrial, decorrente dos avanços sientema se e tecnológicos, aponta para a necessidade de alargar fronteiras. O sistema de reproduz assim, com a cxpansão territorial e com a abertura de nov'os campos de

3. O termo modal refere-se à expansão das fomteiras econômicas no sentido de novas modalidades de atividades que se incorporam aos mercados. aumucão no âmbito da produção e da oferta de serviços.

\section{Contexto da Comercializaçāo para o Mercado} Internacional

Vários fatores em conjunto entram em jogo c compõem um painel onde a Varios fatora se desenvolve e onde o chamado "produto turístico" e atividade turistica mercado internacional

comercializado no me diretamente às especificidades da

Um primeiro grupo de fatores refere-se diretamente as especificidades da atividade turist ica na locais com as redes de comercialização internacionalizae prestadores de serviços exterior em moeda estrangeira referenciada à cotação do das; a venda realizada nalcão"s diferenciados daqueles acordados com as agências dólar'; os "preços de balcão de hospedagem e demais serviços locais.

peradoras pelos mo defatores refere-se a formas de organização da economia

Um segundogrupo de fatores refere-se a formas de organizaçãoda bancório e mundial contemporânea: as novas bases de estruturação do sistema bet rônica ${ }^{7}$. traciliode da moeda nacional frente à moeda i iternacional - o dólar.

No interior deste quadro complexo consolidam-se mecanismos de comercialização, que possibilitam a apropriação da renda gerada pela atividade fora dos locaisonde ela éproduzida. Uma parcela significativa dessa renda gerada permanece nas áreas onde o produto é vendido em moeda estrangeira, entrando diretamente nos circuitos superiores do mercado financeiro internacional,

quetemcomo ponto de apoio para seus movimentos especulativos as principais praças financeiras do mundo desenvolvido e como instrumento de especulação o manejo das moedas fortes contra as mais fracas.

Tavares \& Belluzo, 1980:122)

Allos vazamentos têm contribuido para uma decepcionante performance da indústria do turismoe para sua falência em eliminargrandesdéficits da balança de pagamentos. Eles certamente, não se restringemà indústria do turismo, mas são comuns a muitas formas de modernização em paises em está fazendo menos do que pode para reduzir os problemas relativos à balança de pagamentos no mundo em desenvolvimento.

Mathieson \& Wall, 1986:62)

4 Zedolar(...)esta fois

de placoment" (Gois I' unite de compte, la monnaiedes reglements intemationaux, la monnaiede réserve etl' instrument 5. Propus dos servicos cobger, 1986:54)

Q il labanque életronipados aos usuários diretamente sem intermediação de agente

of de contrecaner les reglemerise les murs, elle corrode aussi le frontiers (...). Car elle offre desmoyens de contoumer

"as papier" Def hechiniques informatiques magnetiques, eletroniques et télématiques permettant l' echange des fonds Desiniçăo do "Le Joumal Officiel" de 1982 (apud Goldfinger, 1986:268) 


\section{Mecanismos de Formaçāo de Preços e de Transferência e Retençāo de Renda no Mercado Internacional}

Além de integrar o mercado internacional do ponto de vista do seu consumo, os "produtos turísticos" do Rio de Janeiro são também internacionalizádos no que diz respeito à produção e à oferta dos serviços que os compõcm. O número que empresas estrangeiras e de corporações multinacionais que participam deste
mercado no Rio é cada vez maior. ${ }^{8}$

Considerando-se que metade dos turistas hospedados em hotéis no Rio de Janeiro são estrangeiros ${ }^{9}$, que o turista estrangeiro permanecce em média mais dias no Rio do que o turista brasileiro ${ }^{10}$ e que $71 \%$ dos hóspedes cin liotéis de cadeis internacionais são cstrangeiros contra $49 \%$ nos hotéis nacionais ${ }^{1:}$, constata-se que uma parcela significativa do total de demanda turística intemacional para a cidade consome os serviços oferecidos nos hóteis operados por grupos estraligeiros.

Dadas as condições da sua comercialização no Exterior, onde as empresas exploradoras destes meios de hospedagem têm suas sedes c matrizes, parte do cxcedente e da renda gerados ficam retidos fora, sendo remęida para o Brasil a parcela relativa aos custos de produção dos serviços. Mesmo una parte destes custos de produção dos serviços podc, ainda, ser coberta com o excedente gerado em moeda nacional pelo consumo no mercado interno, o que propicia, por compensação, um aumento do excedente retido no Extcrior.

Por outro lado, no que diz respeito à formação de preços no mercado internacional, a grande distância que separa o Brasil e o Rio de Janeiro dos principais pólos emissores de demanda dos países desenvolvidos pesa na competitividade dos "produtos turísticos" brasileiros, em função da alıa participação do custo do transporte por unidade de produto comercializado

Outros destinos de clima tropical e subtropical mais próximos dos Estados Unidos c da Europa, como a região do Caribe c a América Central para os primeiros e os países da Costa Mediterrânea para a última, podem oferecer, em função desta proximidade, um preço composto final com menor participação percentual do item transporte. Isto sem considerar a concorrência interna ao próprio grupo dos paises ricos.

\footnotetext{
8. Emtorno de $30 \%$ das agências locais que operam com o receptivo intemacional são empresas vinculadás a $3 \bullet$ capital extemo. em sua maioria filiais de cadeias internacionais de agências de viagens Com reiação aos mcios de hosped dagem, dos onzze hotéis categoria cinco estrelas em operacăo no Rio, cinco são ligados a cadeias internacionais, oferececendo 1.93 2 unidades habitacionais, que correspondem a $4.4 \%$ do total oferecido a catoria (Estimativa embasada em pesquisa de campo. em consulta a publicą̧̃̃es especializadas e em contatos com profissionais do setor.

9. Extraido dos dados das Fichas Nacionais de Registros de Hóspedes (FNRH) tabuladis pelo setor de es statistica da Turistio

para os anos de 1988 e 1989 ( janeiro a julho).
10. A principal motivą̧ąo de viagem para os brasileiros que se hospedem em hóteis classiticados são os negécios (52:\%) o que leva a uma curtapermanencia na cidade. Extraído dos dados das Fichas Nacionals de Registro. e 1989, janeiro a julho).

em com dados extraidos das lïchas Nacionais ou Registro de Ilóspe:des. nu Ferioju de janeiro a dezembro de 1991 .
}

Agravando, ainda mais, a competitividade com destinos mais proximos, Agravandartização dos serviços turísticos resultante do "padrão - procesSO de estano pela sua comercialização e produção internacional izadas modernizante" imposlação de informações do mundo moderno consolidam e a fantástica cícos" cada vez menos exclusivos e locais, e cada vez mais "produtos turisticesuzindo a potencialidade destes lugares na obtenção de um cosmopolitas ${ }^{12}$, reduzindo

cosmopolitas

Todos estes fatores, em conjunto, pressionam para baixo o preço do "produto Todos ester mo mercado internacional ${ }^{13}$. Indicador deste baixo custo dos turistico" brasileiro no mós, o gasto médio diário do turista estrangeiro no Brasil é serviços turisticos no Pédio do turista brasileiro no Evterior (Embratur s.d.). Isto menor do que o gasto mécios de hospedagem em considerar que os brasileiros, em media, utilizam-se de meios de hospedagem de tegoria inferior, comparados àqueles utilizados pelos estrangeiros no Brasil É importante observar que os meios de hospedagem no Brasil são classificados e E importante um controle de qualidade que obedece parâmetros rígidos ditados por uma matriz de padrão internacional.

Observe-se, ainda, que os países ricos, além de receberem os maiores fluxos turísticos internacionais, se apropriam proporcionalmente da maior parcela de renda gerada. ${ }^{14}$

Por força destes mecanismos estruturais e conjunturais e das pressões das limit ções do pouco estimulado mercado interno, as empresas prestadoras de servicos locais reduzem seus preços nos acordos com as operadoras, de modo a garantir uma taxa de ocupação que viabilize a sua manutenção no mercado. Submeter os seus produtos às redes internacionais de comercialização é, para estas empresas, a condição para atingir esse mercado ${ }^{15}$. O produto turístico não pode ser estoc do. Uma diária de hotel não consumida é um produto não realizado.

A diferença entre o preço praticado com as operadoras e o "preço de balcão" deve ser sufuciente para remunerar todos os agentes que participam de uma cadeia de comercialização. Da operadora local até à última agência varejista que vende o produto diretamente ao consumidor final, esta cadeia pode envolver até quatro agentes.

quase imar. eus olhos as pais, transladados por mesmos tipos de cabine de avião, de pullman, de quartos de hotel, vendo diante de 13. "The dollar goes a lons wue ja viram cem vezes nas telas da $T V$, ou nos prospectos turisticos" (Guattari, 1990:4). Maribean even lo

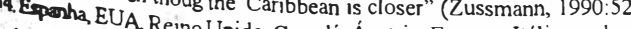

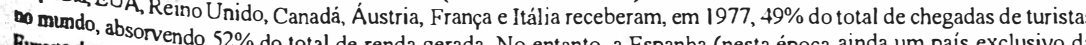

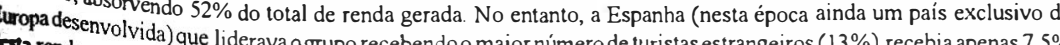

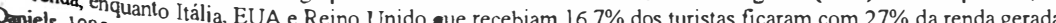
15. Esta submissão

beteliras que âs redes de comercialização não se aplica aos hotéis de cadeia internacional e às grandes empresas on contato com têm escritórios de representação nos principais pólos de emissão de turistas no Exterior. Diretamente adeias de con mercados consumidores, estas empresas escapam das comissões que remuneram alguns elos das de comercializąåăo, garantindo assim um sobrelucro sobre os seus servif̧os. 
Esta diferença é uma parcela do preço de mercado que é realizado quando o produto é comercializado diretamente, e que deixa de ser apropriado pelo quando local, sendo transferida aos agentes que promovem a sua comercialização localutor dos no Exterior.

Mesmo uma parcela das comissões que remuneram as agências operador locais acaba sendo mantida em moeda estrangeira no Exterior. Grande parteras agências operadoras, locais e externas, atuam ao mesmo icmpo no sezte das receptivo e no emissivo dos seus respectivos países, estabelecendo um canal únio de comercialização e de circulação de moeda com fluxos nos dois sentidos entradas e saídas. A instantaneidade das informações, proporcionadidos tecnologias modernas, viabiliza uma forma particular de contabilidade entre estes agentes locais e externos. O fluxo de informaçõcs substitui a circulação de moedas e somente o resultado da operação (entissivo $x$ receptivo) é que se realiza no interio de um mesmo canal de comcrcialização.

Um mecanismo de compensação automático, interno à contabilidade desses dois agentes, permite que os valores em moeda nacional, referentes ao pagamento dos produtos do exportativo aqui vendidos, acabe servindo para cobrir os custos dos serviços locais que são comcrcializados no Exterior e vice-versa.

Como resultado desta operação, parte da remuneração daagência operadora local relativa ao lucro, tanto do receptivo quanto do exportátivo, pode ser mantida em moeda estrangeira no Exterior. Evita-sc desta forma a passagem pelo sistema bancário nacional que obrigaria sua conversão em moeda nacional para uso no País.

No caso das agências locais, cujo controle do capital é externo, a operação desta contabilidade e compensação interna de moedas é muito mais simples, uma vez que os preços do tarifário repassados para as matrizes são os preços de custo "preço net" - dos serviços, sendo por clas definidas c adicionadas as comissões que são retiradas fora.

No regime capitalista, ondea lei fundamental é a da acumulação de capital o mais rápido possivel, os fluxos de excedentes só podem convergir para o lugar onde se encontram os mecanismos mais eficazes para a sua multiplicação.

(Santos, 1975:16)

Estes mecanismos possibilitam a constituição de uma poupança externa em moeda estrangeira, constribuindo para a acumulação fora do país. Segundo Goldfinger (1986:103-4):

\footnotetext{
16 “Gràce a magie de la technologied" infomacion les monnaies sont simultanément àl' interielur et al' exterieur. les "Gràce a la magie de la technologie d" informacion, les monnaies sont simultanément àl " inceles mouvements globaux banquessont etroitement contrôlees et trés libres, la geófinance est transparent topaque... Ainsi nait le phenoméne de la xenomonnaie, de la monnaie étrangére. (Godfinger, 1986:103-4).
}

Graças a magia da tecnologia de informação, as moedas estão simultaneamente no Grą̧as a magia da bancos são estreitamente controlados e muito livres, a geofinança interior e exterior, os baca. Os movimentos globais do dinheiro criam aglomeraçóes de $\dot{e}$ transparenta dos seus paises de origem. Dessa maneira nasce o fenômeno da

moedas fora do seja da moeda estrangeira". ${ }^{16}$

As condições especificas da produção e da comercialização dos serviços As con Rio de Janeiro para o mercado internacional oferecem cstas possibitunsticos do Rara aglomeração de moeda fora do País, propiciando que uma parcela do lidades para a a gerados pela atividade sejam retidos e apropriados no Exterior em

valor e da renda geradia estrangeira.

Todos estes mecanismos contribuem para acumulação e a concentração de apitais nos centros de controle da economia mundial e do sistema financeiro internacional, em prejuizo do processo de acumulação em moeda nacional.

\section{Consideraçōes Finais}

Ocomplexo quadro, que caracterizaas esferas da produção e comercialização dos serviços turísticos do Rio de Janeiro para o mercado internacional, aponta para a 000 rência de mecanismos muito singulares à atividade, no que diz respeito aos processos de circulação do valor, renda e excedente que são por ela gerados.

Estas singularidades, analisadas à luz de processos mais amplos relacionados às formas de integração econômica de lugares e regiões desigualmente desenvolvidos, constituem-se em particularidades do atual estágio do desenvolvimento capitalista e da mundialização da economia.

Áreas centrais e periféricas se integram aos circuitos modernos da produção edacirculação com papéisdiferentes. Asperiferias são predominantemente "locus" de produção da atividade, dadas às limitações estruturais dos seus mercados internos de consumo. As áreas centrais constituem-se ao mesmo tempo em "locus" de produção e mercado de consumo para si próprias e para as periferias. São formas de organização do espaço capitalista não exclusivas do turismo.

$\mathrm{O}$ turismo receptivo internacional no Brasil e no Rio em particular, tem se mostrado um campo fértil à acumulação e, neste sentido, tem atraído capitais externos que atuam tanto na esfera da produção e oferta de serviços locais, quanto nua comercialização. Cadeias internacionais de hotéis e agências de turismo atrangeiras compõem, cm conjunto com as empresas nacionais, o universo de gentes que produz e vende o turismo do Rio de Janeiro no mercado internacional. Em certa medida, o turismo define uma forma de participação do Rio de e do Brasil na divisão internacional do trabalho.

No contexto da economia mundializada, e das novas tecnologias de comunicação utilizadas, a atividade turística deve ser analisada, buscando esclarecer os mecanismos que possibilitam a ocorrência de formas específicas de circulação do valor e renda que são por ela gerados. 
Além das condições gerais que determinam a internacionalização da produção e a integração dos lugares periféricos, seduzindo e atraindo os capitais externos, a comercialização dos serviços turísticos, fora das fronteiras do País vantajosa para as empresas estrangeiras constituidas sob a formas do Pais, internacionais.

Em primeiro lugar, estas empresas estão em contato direto com os principais mercados de consumo, não necessitando, obrigatoriamente, intermediação agências operadores para comercialização do seu produto, c garantindo, assima das totalidade do excedente produzido. As empresas locais, principalmente as pequeno e médio portes, são, neste sentido, totalmente dependentes dos agentes que constituem as redes internacionais de comercialização.

Em segundo lugar, as vendas realizadas diretamente no Exterior em moed estrangeira permitem a retenção do excedente fora do País, inclusive de uma parcel do excedente relativo às vendas para o consumo do mercado nacional, por via de um mecanismo de compensação automática interno às empresas.

Por fora de um mecanismo semelhante, ocorre a possibilidade, também, de que o excedente gerado nas empresas nacionais, que atuam na comercialização, possa entrar diretamente nos circuitos externos de circulação em moeda estrangeira. A histórica fragilidade e instabilidade da moeda nacional favorecem esta possibilidade de retenção de renda em moeda estrangeira no Exterior, o que, por sua vez, acentua esta fragilidade.

Apesar do seu forte e tradicional apelo como lugar turístico, o Rio de Janeiro é um destino distante com relação aos principais mercados consumidores, comparativamente a outros destinos "tropicais". A alta participação do item transporte na composição final dos preços dos "produtos turísticos" acaba impondo a redução dos preços dos serviços turísticos locais.

No âmbito do mercado internacional, onde produtos turísticos de várias nacionalidades são ofertados e vendidos, a prática desses preços mais baixos por alguns países consolida mecanismos de transferência geográfica de valor, onde uma parcela do valor produzido num lugar é, pelo menos parcialmente, realizado e contribui para a acumulação em outro lugar. Esta é uma forma de integração tipica dos países do Terceiro Mundo e dos lugares periféricos e semiperiféricos à escala internacional. É um processo que se reproduz em outras escalas.

No caso dos serviços turísticos produzidos no Rio de Janeiro para o consumo do mercado internacional, esta transferência de valor se dá através de formas que se merpõem: na retenc̃o diretamenteno Exterior de uma partedos evcedentes que Se superpõem: na retenção diretamente no Exterior de uma partedos exceden fatores
são aqui gerados e no custo mais baixo do produto, proporcionado, além dos fatore expostos, também pelo baixo custo da força de trabalho no País

Sem entrar no mérito da polêmica discussão teórica sobre a formação de valor na economia dos serviços, entende-se que, em função da interpenetração cada vez maior dos setores tradicionais da economia, é inquestionável a par ticipação dos serviços na formação da riqueza e na geração de renda que vão embasar o processo de acumulação.

Interessa destacar a importância que a cconomia do turismo assume no acumulação atual proporcionando, ao nível da mundialização da rrocesso de acuscas da produção e da circulação, uma forma particular de economia nas es produção do espaço dialeticamente homogêneo e fragmentado. "integração" e de produçantração da acumulação de renda e excedente fora do lugar Contribuindo paraa

onde eles são gerados, a econo

Sem deixar de reconhecer o turismo como uma atividade genuinamente Sem deixá conclui-se que a sua capacidade de "geração de divisas" deva exportadora do pelos mecanismos de "drenagem" descritos, abrindo espaço para ser relativexão crítica sobre o tema.

\section{REFERÊNCIAS BIBLIOGRÁFICAS}

DANIELS, Peter. 1985. Service industries. A geographical appraisal. New York: Methuen, 322p. DANIEL, 1984. Brasil. Desempenho do turismo emissivo e receptivo. Embratur, $27 \mathrm{p}$.

EOAT $423 \mathrm{p}$.

GUATTARI, Félix 1990. Restar

(Caderno Idéias, Ensaios)

LPIETZ Alin 1988. O capital e seu espaço. São Paulo: Nobel, 209 p.

MATHIESON, Alister; WALL, Geofrey. 1982. Tourism. Economic, physical and social impacts. London: Longman, $208 \mathrm{p}$.

SANTOS, Millon. 1975. Espaço e dominação (Traduzido de Revue Internacionale des Sciences Sociales, n. 2, por uma equipe de tradutores da AGB - SRSP).

SOJA, Edward. 1983. Uma concep̧̧ão materialista da espacialidade. In: BECKER, B; COSTA, R. SILVEIRA, C. (orgs.). Abordagens politicas da espacialidade. Rio de Janeiro: UFR , p. 22 - 74. TAVARES, Maria da Conceição; BELLUZZO, Luiz G. de Mello. 1980. O capital financeiro e empresa multinacional. Temas em Ciências Humanas, São Paulo, n. 9, p.l 13-24.

ZUSSMAN, Mark. 1990. Tours Brasil wants your clients samba-ing in Rio. Travel World - The Monthly Review for Travel Agents. Norwalk, jan., p. $51-3$.

EMRAT. S.d. Brasil. Pesquisa sobre o turismo receptivo e turismo emissivo. (Pesquisa amostral 1985/ 1990). Embratur. 